\title{
The Problem of Creation and Abstract Artifacts
}

\section{Nurbay Irmak}

Accepted manuscript, forthcoming in Synthese. The final publication is available here.

ABSTRACT: Abstract artifacts such as musical works and fictional entities are human creations; they are intentional products of our actions and activities. One line of argument against abstract artifacts is that abstract objects are not the kind of objects that can be created. This is so, it is argued, because abstract objects are causally inert. Since creation requires being caused to exist, abstract objects cannot be created. One common way to refute this argument is to reject the causal inefficacy of abstracta. I argue that creationists should rather reject the principle that creation requires causation. Creation, in my view, is a non-causal relation that can be explained using an appropriate notion of ontological dependence. The existence and the creation of abstract artifacts depend on certain individuals with appropriate intentions, along with events of a certain kind that include but are not limited to creations of certain concrete objects.

KEYWORDS: ontology, abstract objects, artifacts, creation, ontological dependence, musical works

Abstract artifacts are the kind of abstract objects that are intentional products of human actions and activities. Musical works, novels, fictional characters, and computer programs are all abstract artifacts. They are the creations of writers, composers, computer programmers, linguistic communities, and so on. Call this view "creationism about abstracta" or simply "creationism."

One persistent problem which besets creationist views is that abstract objects are not the kind of entities that can be created and thus, the objects in question are not artifacts. Call this the argument against creation (No Creation). Assume that $x \mathrm{~s}$ are the kind of entities such as musical works, fictional characters, words, and letters. No Creation can be stated as follows: 
(A1) $x$ s are abstract.

(A2) Abstract objects are causally inert entities.

(A3) If one creates something, one causes it to exist.

(A4) Therefore, $x$ s are not created.

No Creation plays an important role in motivating Platonism about the kind of objects listed above, which is, roughly, the view that classifies these objects as eternal, causally inert, and non-spatiotemporal entities. Platonists argue that No Creation provides compelling evidence against creationism, which, at least prima facie, seems like quite a reasonable view to have about the objects in question. ${ }^{1}$ Some creationists respond to No Creation by rejecting (A2). They argue that abstract objects such as musical works or fictional entities may enter into causal relations, thus rejecting that abstracta are causally inert (Howell 2002, pp.117-8; Trivedi 2002, p.79; Walters 2013, p.469). The disagreement about (A2) is a disagreement about the correct ontological categorization of certain kinds of abstract entities or their metaphysical nature and it cannot easily be resolved, it seems, as the very criteria for abstractness are challenged and under discussion..$^{2}$ Fortunately, we do not need to take sides in this debate here as I will argue that creationists need not reject (A2) to resist the argument against creation. No Creation fails, or so I will argue, because (A3) is false. ${ }^{3}$ One of the main goals of this paper is to show that

\footnotetext{
1 See Dodd (2000, p.431), Katz (2000, p.148) and Cameron (2012, p.180) for arguments that are similar to No Creation.

2 See Rosen (2001) and Caplan and Matheson (2004, pp.117-122) for a critical examination of (A2).

${ }^{3}$ I am leaving aside the nominalist option (the rejection (A1)), for my purpose here is to defend creationism against the competing Platonist views about the entities in question.
} 
creationism is not only a very intuitive view about these objects, but also a metaphysically viable theory which cannot easily be set aside as some mysterious view that relies on obscure, non-standard ontological principles.

In section 1, I will argue that creation, at least in the case of abstract objects, is non-causal. Non-causal creation as a view that provides a metaphysical explanation for the creation of abstracta has been mostly ignored in the literature, or if it is considered at all, it is summarily dismissed, as it is assumed to rely on some metaphysically esoteric understanding of creation or causation. My aim in section 2 will be to develop an account of non-causal creation that is built on a relatively standard theory of ontological dependence. To illustrate how this account works, I will take Jerrold Levinson's creationist account of musical works to show how his creationism - revised minimally via the notion of ontological dependence - can easily remove the aforementioned accusations of mystery. Finally, I will respond to some of the potential objections to non-causal creation.

\section{Creation, causation and abstracta}

Creation is usually taken to be a causal activity: causing something to exist. There are, of course, exceptions. Harry Deutsch, for instance, argues that creation might be an act of stipulation that does not require a causal interaction between an agent and an abstract object:

We shall find that in general creating a work of art (or an object thereof), including a painting or sculpture, has far less to do with bringing anything into existence than might be supposed. [...] To be in a position to create a 
thing is to be in a position to stipulate, rather than to merely describe, what the thing is like. [...] It is possible to stipulate what a thing is like without bringing a thing like that into being, provided we assume in advance that whatever may be the content of the stipulation, in some sense there is already a thing like that (Deutsch, p.211-2).

One persistent objection to Deutsch's view is that stipulative creation is not really a creation. The idea that creation requires causation is prevalent, especially among those who argue against creationism. That this is so is evidenced by the fact that anti-creationists take (A3) to be intuitively obvious. Stuart Brock, for instance, insists that creation requires being caused to exist:

We will say that causal creation is the process of bringing something into being or causing it to exist. My view is that Deutschian creation isn't a kind of creation at all; causal creation is the only variety of genuine creation (Brock, p. 343).

Another example is Julian Dodd, who simply asserts that creation requires causation:

The creation of an abstract object would have to be a kind of causal interaction between a person and an abstract object or objects; and abstracta cannot enter into such interactions (Dodd 2000, p. 431).

One way to understand the above claim is that in order to create an abstract object, $x$, one must be able to causally interact with $x$, namely causing $x$ to exist. Since $x$ is not the kind of entity that can participate in causal relations (assuming (A2) is true), $x$ cannot be the kind of object that can be created. This would be a very bizarre 
view of creation. Notice that whether or not the created object is capable of taking part in causal interactions is not the issue here. Rather, the issue is whether creation as a particular kind of productive action is causal in nature. The main problem with this view, as I see it, is that it conflicts with how we usually think creation occurs, even in paradigmatic cases of concrete artifacts. Imagine a carpenter making a table. Does the creation of the table require that the carpenter causally interact with the table, the very product of his creative activities? I liken this to putting the cart before the horse. Prior to the carpenter's completing his work, the table doesn't exist. What he is causally in contact with is some concrete material - a piece of wood, for instance. The table is the result, the end product of his creative activities, yet the very creation of the table does not require that he causally engage with the table before the completion of his work.

There are good reasons to think that this is not the right interpretation of Dodd's causal requirement. After all, what he says is that creation requires a causal interaction between an agent and an abstract object. This abstract object need not be the result of creation. Take musical works. Dodd argues that creating a musical work would require that some agent be in a position to influence, manipulate or interact with some abstract object, a pure sound structure. This interaction is causal in nature. The assumption that creation requires causation seems to be supported by Levinsonian theories of indicated types, where a composer creates a musical work by an act of indication, selection, or determination of a pure sound structure. ${ }^{4}$ I

${ }^{4}$ Creationist authors in the ontology of music do not explicitly share this assumption. However, the terminology they use; i.e. indication, selection, or determination to describe the act of musical creation is amenable to being interpreted as a causal relation (Levinson 
will argue that this assumption is false: the creation of a musical work does not require that a composer be able to causally interact with a pure sound structure.

Although there is not yet a fully developed account of non-causal creation of abstract artifacts, the possibility of dismissing a causal criterion for creation has been briefly entertained in the literature. Such an account, it is argued, would have to rely on some non-causal metaphysical relation (employed as a generative relation) that could replace causation for the creation of abstract artifacts. However, the argument continues, exactly how an abstract object is brought into existence by virtue of this metaphysical relation remains a mystery. Thus, any account of noncausal creation will either fail to provide a metaphysical explanation for the creation of abstract artifacts, or it will end up relying on some obscure view about the nature of the metaphysical relation in question. Christy Mag Uidhir, for instance, argues that such a view would leave the creation of abstracta a metaphysically mysterious phenomenon, even though one might accept an alternative notion of creation where creation is a matter of ontological dependence:

One need then simply deny that creation strictly requires causation via committing to some non-standard (and likely stipulative) sense of create according to which creation minimally need be neither causal nor causalintentional but merely a matter of ontological-dependence. [...]

(1980, pp.21-2); Howell (2002, p.107); Trivedi (2002, p.78)). Evnine (2009, p.215; 2016, p.137-8) is one exception. He argues that one can act with respect to the matter without causally manipulating it. The composer's work does not modify the sound structure in a causal manner but "involves selection and display." Although different from mine, Evnine's conception of creation is also based on the rejection of (A3). 
Additionally, without a strict causal requirement for creation, the precise nature of how such abstracta could come into existence-whether in number modest or absurd—would nevertheless conspicuously remain metaphysically mysterious (Mag Uidhir 2012, p. 15). ${ }^{5}$

French and Vickers raise a similar worry:

A closely related option would be to argue that although creation does require causation (in some sense), and we can't causally interact with abstract objects, this in itself doesn't mean that we can't create abstract objects. After all, during the process of creation the abstract object doesn't yet exist, so one is free to tell a story where we manipulate things we can causally interact with, and the abstract object comes about as a result of our manipulating these things. But the obvious concern is similar to that discussed above: quite how the abstract object comes into existence remains a mystery, a mystery which renders this option most unappealing, in our view (French and Vickers, pp. 781-2).

I take it that the worry about mystery is not about the nature of ontological dependence itself. After all, a quick survey of the literature on ontological dependence and grounding will reveal that it is as mysterious as any other metaphysical relation. ${ }^{6}$ Rather, they argue that relying on ontological dependence

\footnotetext{
5 In all fairness, Mag Uidhir raises further problems with this alternative. I address these problems below.

6 The use of ontological dependence in metaphysical theories goes back to Aristotle (Corkum 2008). More recent accounts of ontological dependence, such as Lowe's, reveal a family of relations that can potentially explain the relation between sets and their members, wholes and their parts, holes and their hosts, tropes and their bearers, etc. (Koslicki, p. 31).
} 
does not explain exactly how abstract artifacts, by mere instantiation of this metaphysical relation, are brought into existence. If an account of non-causal creation has any chance of success, it must at least satisfy the following explanatory demands. First of all, it must explain how ontological dependence works in the case of abstract artifacts. Second, it must explain exactly how an appeal to this metaphysical relation removes the worries about the mystery mentioned above. In what follows, I will lay out the basic theory of non-causal creation and expand on it by providing a simple illustration of how it works in the case of musical composition, which, with minor modifications, can be extended to other abstract artifacts. I will then show that in certain circumstances ontological dependence can be generative, that is, its instantiation can generate or produce new entities that did not exist before. I will argue that the generative nature of ontological dependence can successfully address the question of how its instantiation explains the creation of abstract artifacts. The main point is that there is nothing metaphysically mysterious about non-causal creation. Finally, I will answer potential objections to the non-causal theory of creation.

\section{Non-Causal Creation and ontological dependence}

Various kinds of non-causal metaphysical relations such as grounding, ontological dependence and emergence can be employed for one's preferred account of noncausal creation. Each relation has its advantages and disadvantages. ${ }^{7}$ Thankfully, for the purposes of our discussion here, it is not necessary to take sides in this debate.

\footnotetext{
7 For comparative evaluations of these relations see Fine (1995), Correia (2005; 2008), Koslicki (2013), Hoeltje, Schnieder, \& Steinberg (2013), Tahko and Lowe (2015), and Schnieder (2020).
} 
The main argument of this paper is neutral in terms of which particular metaphysical dependence relation one chooses to employ in an account of creation in so far as the relation in question is non-causal and generative. The account of non-causal creation I develop here relies on the notion of ontological dependence. This choice is partly motivated by the account developed by Amie Thomasson in her Fiction and Metaphysics (1999, pp.24-42) where she clarifies and argues for various kinds of ontological dependence and provides an application for fictional characters. ${ }^{8}$ Thomasson, however, is not directly concerned with the creation problem for abstract artifacts. In a way, the particular account below is further continuation of her project and its defense against one of the major arguments against abstract artifacts. One important difference that should be emphasized is that I, pace Thomasson, do not commit to the idea that the modal existential dependence explains the metaphysical relations between abstract artifacts and concrete individuals, properties, or events. It may turn out, for instance, that ontological dependence is too coarse grained to be a suitable relation for the kind of entities in question. In that case, creationists might appeal to metaphysical grounding instead to explain how abstract entities are brought into existence. This flexibility is justified given that the main purpose of this paper is show that No

\footnotetext{
8 Thomasson has abandoned some of her claims about the metaphysical nature of dependence relations between abstract artifacts and the creative activities of their authors. In her more recent work, Thomasson argues that the artifactual theory of fiction she developed in Fiction and Metaphysics should be combined with her deflationary metaontology (Thomasson 2007, pp.110-125; 2015a, 2015b, pp.258-262). Although I am sympathetic to her metaontological views, the argument of this paper does not require any commitment to a particular metaontological theory.
} 
Creation can be resisted without committing to some non-standard, metaphysically mysterious notion of creation.

On this view, roughly, the existence of an abstract artifact depends ontologically on various individual objects and events. These objects and events constitute the dependence base of an abstract artifact. In the case of musical works, the dependence base includes particular individuals such as composers with the right kind of intentions (i.e. intending to create a musical work), a musical community, the creation of a certain kind of concrete objects such as the original score and its copies, the creative activities of composers, and various activities in which the relevant musical community participates.

There are two main alternative accounts of ontological dependence: modallogical and essentialist accounts. I will not go into reasons for which one might favor one over the other. ${ }^{9}$ My purpose here is not to defend any particular account of ontological dependence; rather, it is to show that creationists can provide a noncausal account of creation based on a rather standard theory of ontological dependence. With this purpose in mind and for reasons of simplicity, I will choose one of the accounts that are readily available in the literature and show that creation taken as a phenomenon that relies on ontological dependence is not as miraculous or metaphysically mysterious as its opponents think. One such relatively simple but useful account of ontological dependence is called rigid existential dependence ${ }^{10}$ :

\footnotetext{
${ }^{9}$ Although see Fine (1995) and Koslicki (2013).

10 For a discussion on different kinds of ontological dependence relations see Thomasson (1999, p.24-34), Correia (2008), and Koslicki (2013).
} 
(RED) $x$ depends for its existence on $y$ if and only if necessarily, $x$ exists only if $y$ exists.

(RED) is rigid because the existence of $x$ depends on a particular object $y$. For simplicity, I will assume that $y$ ranges over individual objects, events, properties, and times. Thus, there is no restriction on the ontological category of objects that can occupy $x^{\prime}$ s dependence base. A set, for instance, rigidly existentially depends on its members. It cannot survive the loss of any of its members. Similarly, on certain accounts of personal identity, a person's existence rigidly existentially depends on her parents. Various creationist accounts in the literature of the ontology of art can help us see how (RED) can provide a straightforward answer to the problem of creation. Levinson's theory of musical works as indicated types, one of the most prominent creationist views of musical works, is such an example. According to Levinson, a musical work MW is an indicated type, a kind of complex abstract structure that is brought into existence by a composer at a certain time. More specifically, in Levinson's view, a musical work composed by X is a sound/performance means structure (S/PM)-indicated by X-at-t (Levinson, 1980, p. 20). The S/PM-indicated by X-at-t is a complex structure that has the sound/performance structure, the composer and the musico-historical context as its essential parts. The non-causal creationist reconstruction of Levinson's view is the following:

(RED-MW) MW depends for its existence on S/PM, X, X's indicating S/PM at time $t$, if and only if necessarily, MW exists only if S/PM, X, X's act of indication of S/PM at time t exist. 
In other words, MW's existence rigidly existentially depends on the composer, the particular sound and performance means structure indicated by the composer, and the particular time it was composed. Any changes in what MW depends on will result in a different musical work. One important advantage of (RED-MW) is that it requires no radical changes to Levinson's original theory. It provides, for instance, the exact individuation conditions (assuming that these conditions are derived from what a musical work existentially rigidly depends on) for musical works, as Levinson argued and for which he was much criticized (Levinson, pp. 12-14). It is important to note here that I am not endorsing (RED-MW). Given that the main goal of this paper is to defend creationist views about abstract artifacts against the No Creation argument, the point of this illustration is to show how the non-causal theory of creation can support the creationist views that have been articulated and defended in the literature.

(RED-MW) explains how ontological dependence relates a musical work to its complete dependence base. However, it is not clear how the mere instantiation of this relation brings about a new entity, a musical work. This was the worry raised by Mag Uidhir, and French and Vickers. The alleged mystery is resolved once we see that ontological dependence can be generative. We can say, roughly, that a relation is generative if and only if its instantiation brings something into existence (Trogdon, pp.189). Regardless of whether a given generative relation is synchronic (i.e. it holds at a single time) or diachronic (i.e. it unfolds over time, as Bennett puts it (2017, p. 85)), its instantiation adds something new to the world that was not there before. Causation as it is characterized in the No Creation argument (i.e. 
creating something is causing it to exist) is a generative relation in this sense: 11 Causes produce their effects. ${ }^{12}$ Many non-causal synchronic metaphysical relations such as composition, constitution, and set formation are generative relations. Their instantiation results in the existence of additional items in our ontology. Take composition, for instance. Assuming that composition is not identity (i.e. the parts are not identical to the whole), if $x$ s compose $y$, the existence of the $x s$ and the instantiation of the composition relation generate a distinct entity, $y$. The question whether or not composition is restricted has no bearing on the generative nature of the composition relation. That is, when composition occurs (or when the composition relation obtains) a new entity, which is not identical to any of its proper parts comes into existence regardless of the restrictions (if any) one might impose on composition. These examples help us further specify our rough characterization of generative relations above. That is, a relation (or its instance) is generative just in case (i) a numerically distinct entity comes into existence as a result of its instantiation and (ii) the generative relatum, i.e. the parts, the causes, the members, and the instantiation of the relation guarantee the existence of a new entity, event, or a property.

\footnotetext{
${ }^{11}$ Bennett (2017, pp.71-83) argues that causation, along with grounding, composition, and realization, is what she calls a building relation. In her view, building relations as a unified family share certain central features such as directedness, necessitation and generativity. Notice that the proponent of No Creation needs to commit only to the generativity of causation.

12 This characterization of causation relies on a common idea that causation is a productive relation. Since No Creation argument requires a productive or a generative conception of causation, I will ignore the problems and complications that come with this view. For a discussion of a productive notion of causation, see Psillos (2002, p.6).
} 
Given these conditions for generativity, it seems clear that ontological dependence, or its modal existential variety that I employ here, is not necessarily a generative relation. Take, for instance, the ontological dependence between events and their participants. The assassination of Caesar depends for its existence on the existence of Caesar, and yet the existence of Caesar does not necessarily bring that very event into existence (Tahko \& Lowe, 2015). Another example where ontological dependence fails to generate new entities comes from the fact that rigid existential dependence is reflexive: any given object rigidly existentially depends on itself (Correia 2008, p.1023). Hence, this particular form of dependence does not generate numerically distinct entities. From these examples, it seems obvious that the previous examples of ontological dependence fail both conditions ((i) and (ii) above) of generativity. ${ }^{13}$ The first case of ontological dependence, i.e. an event's dependence on some of its participants, fail to satisfy (ii) as the existence of the dependence base does not guarantee the existence of the dependent object. The second case, namely self-dependence, on the other hand fails to satisfy (i) as nothing new comes into existence as a result of the dependence relation. There are, however, clear cases of modal existential dependence where the existence of the dependence base and the instantiation of the dependence relation satisfy both conditions. Take, for instance, the ontological dependence between the Eiffel Tower and its unit set or singleton. Arguably the singleton does not exist prior to the

\footnotetext{
13 Notice that an alternative account of non-causal creation that makes use of metaphysical grounding instead of modal existential dependence would be free of this problem. Bennett (2017, p. 12), Schaffer (2016, p. 82) and Trogdon (2018, p.189) argue that grounding satisfies both conditions and thus it is a necessarily generative relation.
} 
existence of the Eiffel Tower. ${ }^{14}$ When the Eiffel Tower is brought into existence, a distinct but a dependent entity, its singleton, comes into existence. It is easy to see how this particular dependence satisfies both conditions of generativity: the singleton is a distinct entity that comes into existence as a result of the existence of the Eiffel Tower. Further examples of such cases include the dependence of holes on their hosts, and boundaries on bodies, etc. (Koslicki, p.31). In all these cases (i) is satisfied as the existence of the dependence base, i.e. the particular elements, hosts, or the bodies, and the instantiation of the particular ontological dependence relation bring numerically distinct entities, i.e. sets, holes, or boundaries, into existence. Similarly (ii) is satisfied as in each case the existence of the dependence base and the instantiation of the particular dependence relation are all it takes for there to exist a new entity. If the above account of generativity is correct, then the particular dependence relation I specified above for musical works (RED-MW) is generative. It satisfies (i) as the musical work is a new entity that is not identical to any of the elements of its dependence base. It also satisfies (ii) because its dependence base jointly guarantees the existence of a musical work. I conclude that although modal existential dependence is not necessarily generative, some of its instances that satisfy (i) and (ii) including (RED-MW) is generative.

It is important to note that not all generations are artifacts or intentional creations. It seems that creation does not necessarily require any intention to bring

${ }^{14}$ Although controversial, the view that impure sets exist when their concrete ur-elements come into existence is quite common. Gideon Rosen attributes this view to David Lewis (Rosen 2001). For others who adopt a similar view see Dodd (2002, p.397), Caplan and Matheson (2004, p.123), Rossberg (2012, p.63), Mag Uidhir (2013, p.140). 
a particular (kind of) object into existence. There is a wider sense of creation in which any object that comes into existence - partly in virtue of some human (or animal) activity - constitutes a created object. Therefore, we need to make a distinction between mere production or generation and intentional creation of objects. ${ }^{15}$ Although different kinds of objects come into existence by the same human activity, it simply is not true that they are all necessarily artifacts (Hilpinen, 2004). Artifacts are intentional creations. Artifact creation minimally requires the intention to bring an object of a kind $K$ into existence, where $K$ is an artifactual kind. Following the distinction between intentional creation and mere production we can distinguish human creations from unintended products of human activity. When an artisan works on some material to create, say a table, often she produces not only the intended object of her work, the artifact, but also some residue - a leftover piece of wood, for instance - as a result of her activities. This residue is not her intentional creation, it's a mere production and hence, not an artifact. However, this is not the only way we create objects that fail to be artifacts. Assuming that mereological sums exist, for instance, whenever an artisan creates an artifact, further objects (a number of mereological sums that take this artifact as a part) come into existence as a result of her intentional creation. These gerrymandered objects, along with the residual material objects, fall under the general category of unintended mere products of her creative activities. Although these further objects — the mereological sum of the table and the Eiffel Tower or the singleton of the

15 A similar distinction is made by Cray (2017, p.291). Cray takes generation to be a broader notion and reserve creation for intentional generation of artifacts. Nothing in our discussion here depends on this terminological choice. 
table - ontologically depend on the creation of the table, their existence does not require an additional intentional activity. In fact, unlike artifacts, the existence of singletons or mereological sums does not ontologically depend on intentional human action, except perhaps those mereological sums or singletons that take some artifact as a part or a member. However, in those cases too, only the existence of the artifact in question requires an intention to create the relevant kind, not the mereological sum or the singleton. Therefore, I conclude that artifact creation is a special case of the general schema of ontological dependence provided above: artifact creation requires that the agent's bringing about the conditions on which $x^{\prime} \mathrm{s}$ existence ontologically depends is intentional. In this view, then, to create an abstract artifact is to intentionally bring about the conditions that are specified in its dependence base. Once all the entities, intentions, and events that constitute its dependence base exist, the abstract artifact comes into existence. These conditions are all that the existence and the creation of the object in question demand. ${ }^{16}$ Bringing about these conditions, of course, requires agents to do some causal work that involves concrete objects and/or events.

One might insist that even if we accept that ontological dependence can be generative, it is still not clear how this account explains the creation of an abstract object. However, once the generative nature of particular ontological dependence relations is granted, I submit that this demand for further explanation is not justified. It seems that no such further explanations are required in cases where other generative relations are in place. In the case of composition, for example, the

16 For a similar view about fictional characters, see Thomasson (1999, pp.25-42). 
existence of parts and the instantiation of the composition relation explain how a further object comes into existence. ${ }^{17}$ Obtaining these facts is all that is needed for the explanation of how $y$ comes into existence as a result of the existence of the $x \mathrm{~s}$ and the instantiation of the composition relation. One might, of course, deny that composition ever takes place or that (unrestricted) composition overpopulates our world without necessity and thus violates the principle of parsimony, or that composition leads to accepting into our ontology far too many objects that are not compatible with our common sense or ordinary beliefs about the world. However, these objections mainly target the claim that composition occurs, not the weaker conditional claim that if composition occurs, its instantiation would explain how further objects that did not previously exist are generated. If composition takes place between the $x$ s and $y$, there is no further explanation needed to show how the $x$ come to compose $y$. Similarly, if ontological dependence holds between an abstract object and its dependence base, there is no legitimate demand for further explanation as to exactly how the abstract artifact is generated. Therefore, the demand for further explanation is misplaced; there is nothing more to explain.

I argued above that bringing about the conditions for the existence of an abstract artifact involves some causal-intentional work by agents. One might argue that, with this particular requirement, causation is conveniently placed back into my account and thus it is no longer clear why creation in this view is a non-causal activity. It is important here to note that the following questions are different: "Is creation a causal relation?" and "Does creation entail causal interactions between certain

17 I am assuming once again that composition is not identity. 
objects and/or events?" I argue that one could give a variety of different answers to these questions. That is, I argue that one can deny that creation, at least in the case of abstract artifacts, is a causal relation (answering the first question in the negative), and yet require the existence of some causal relations among concrete objects and/or events that are causally efficacious (answering the second question in the affirmative). Creation, in my view, requires causal interactions to have taken place between certain kinds of objects and/or events. These causal interactions are not objectionable to anti-creationists, however, as they occur in the realm of concreta. All entities that participate in these causal relations are concrete. Therefore, (A2) is not violated. In other words, the creation of an abstract artifact is not a kind of action where one causally interacts with or manipulates some abstract object, as anti-creationists such as Dodd assume. Rather, it is a kind action where all one needs to do is to bring about the entities and events on which abstract artifacts' existence ontologically depends.

Once we distinguish non-causal creation and the kind of causation this concept of creation requires, viz. causal interactions among causally efficacious entities, the anti-creationist worry that non-causal creation is metaphysical mysterious should dissolve. In fact, Dodd seems to accept a similar account for the existence of impure sets:

[0]nce the Eiffel Tower was built, the singleton containing the Eiffel Tower thereby came into existence, but the fact that such sets can come in and out of existence does not violate the principle of causal inertness of abstracta: the causal process in this case in involved people and bits of 
metal, the coming to being of the set being an ontological free lunch (Dodd 2002, p. 397) (emphasis mine).

Leaving aside Dodd's claim that the singleton's coming into existence is an ontological free lunch, I am in complete agreement with him in what he says above. More specifically, it seems that Dodd and I agree, at least with regard to the particular example above, that bringing an abstract object into existence does not require a causal interaction between an abstract object and some concrete individuals. The existence of the singleton of the Eiffel Tower ontologically depends on the existence of the Eiffel Tower, whose existence further depends on some causal work done by people on bits of metal. Of course, neither Dodd nor I claim that the singleton is an abstract artifact. Our reasons for denying this claim, however, are quite different. In my view, the singleton of the Eiffel Tower is an unintended product of the people who were involved in the creation of the tower, yet the ontological dependence between the Eiffel Tower and its singleton explains how a new entity, distinct from the tower and its material parts, namely, the singleton comes into existence. Dodd, on the other hand, maintains that an abstract object such as the singleton containing the Eiffel Tower comes into existence as a result of some human activity, but at the same time, he denies that abstract objects such as musical works are artifacts, i.e. intentional products of human actions. The reason for his firm rejection of the latter is that the creation of such entities would violate (A3), the principle that requires creation to be a causal action. One might think there is no tension between these two claims, as (A3) formally stated in No Creation rules out the possibility of intentional creation of abstracta, not their generation or 
production. However, (A3) can be generalized in such a way that not only the intentional creation but also the generation (i.e. the coming into existence) of abstract objects require being caused to exist. Let's call this further principle (A3*):

(A3*): Generating something requires that it be caused to exist.

(A3) and (A3*) express slightly different principles, but the underlying anticreationist intuition supporting (A3) should also, it seems, support (A3*). Granted, $\left(\mathrm{A}^{*}\right)$ is stronger than $(\mathrm{A} 3)$, but if I am correct that the distinction between intentional creation and mere production of objects is that the former requires intentional activity whereas the latter does not demand an intention to bring into existence a particular kind of object, then I do not see why anti-creationists such as Dodd would have a problem embracing ( $\mathrm{A}^{*}$ ) as well as (A3). In the absence of principled reasons by virtue of which Dodd could successfully accept (A3) but reject (A3*), his overall Platonist account and his approach to the existence of impure sets are in tension. The main point of our discussion here is not merely to underline this tension embedded in Dodd's Platonist account, but to conclude that even some anticreationists concede that abstract objects can come into existence without ascribing any causal efficacy to them. The only reason they deny creation of abstract objects is their insistence on (A3). However, once (A3) is rejected, as I think it should be, the creation of abstract artifacts ceases to be a metaphysical mystery.

Before I close, I would like to address a worry raised by Christy Mag Uidhir (2013). It is important to note that Mag Uidhir does not endorse the argument from creation. In fact, he does not raise a principled objection against the view that there 
could be created abstracta. His arguments attempt to show that artworks, or artifacts in general, cannot be abstract entities.

My goal is not to argue against discovery and creation simpliciter but instead simply to show that the discovery-relation and the creationrelation upon inspection fail to be sufficiently substantive when cast as artist-relations for art-abstracta. As such, my arguments should be taken to have little direct relevance for the creation/discovery debate concerning abstract objects, at least over and above entailing that the debate cannot be a debate about artworks (Mag Uidhir 2013, p.147). He concludes that if there are artworks, they must be concrete (p.159). Although Mag Uidhir's overall nominalist argument is not directly relevant to our discussion here, I would like to address a worry he raises that threatens the account of creation I propose in this paper. Mag Uidhir argues that non-causal creation may lead to an untoward proliferation of abstract artifacts:

Furthermore, absent some principled, non-arbitrary distinction between ontologically-dependent things that are creation-compatible (e.g. the manuscript) and those which are creation-incompatible (e.g. its impure singleton), appeal to non-causal creation threatens an unchecked, rampant proliferation of creation, such that, given even a moderately permissive realism about impure abstracta, from but few acts of artistic creation would likely flow transfinitely many created things (p.158). This is an important worry. However, it can easily be put aside if one includes the right kind of intentions (i.e. intending to create a work of art) among the kind of 
things that the existence of a work of art depends on. This additional requirement is not an ad hoc attempt to block Mag Uidhir's worry, as one can distinguish, on a principled basis, creatable abstract artifacts such as musical or fictional works and what he calls creation-incompatible abstract entities such as impure sets. Both sorts of abstract entities come into existence at a certain time and are thus not eternal abstract objects; yet this does not necessarily imply that both are artifacts. The distinction between intentional creation and mere production or artifacts and the unintended products of human activities I made above makes it clear why creationist accounts such as the one undertaken here should not worry about "rampant proliferation of creation." When a composer creates a musical work, further abstract objects - its singleton, for instance — come into being. However, the singleton is not an intentional creation; it is not another artifact that the composer created. Rather, it is a mere product of the composer's creative activities. Therefore, only the musical work is the composer's intentional creation, not some other abstract objects that come into being as unintended products of his creation. Although I have taken an abstract artifact as an example, the same can be said about concrete artifacts. Going back to the example of a carpenter making a table, we have seen that many "creation-incompatible" objects come into existence as she completes her creation. If Mag Uidhir is correct, we should be as worried about "rampant proliferation of creation" in the case of the creation of the table as we are about the creation of the musical work. However, such worries are misplaced, given that there is a principled distinction between artifacts and mere products. 


\section{Conclusion}

The argument against the creation of abstract artifacts plays an important role in motivating Platonist views about abstracta. One common way to defend creationism against the No Creation argument is to reject the seemingly plausible principle that abstracta are causally inert. Although I see considerable merit in this defense, creationist attempts to show the existence of causally efficacious abstracta are far from convincing. In this paper, I provide a different theoretical option in defense of creationism. I argue that the principle that takes creation as a causal relation should be rejected. Creation, in my view, is a non-causal relation that can be cashed out, using an appropriate notion of ontological dependence. I further argued that ontological dependence, like many other non-causal metaphysical relations, can be generative. The generativity of particular ontological dependence relations explains how certain abstract objects are intentionally created. In this view, the existence and the creation of abstract artifacts depend on certain individuals with appropriate intentions and events of a certain kind, including but not limited to creations of certain concrete objects. Although I make use of one particular account of ontological dependence, namely, rigid existential dependence, it is solely for the purpose of illustrating how one prominent creationist account of musical works, namely Levinson's indicated types, when supplemented with an account of noncausal creation, removes the worry that abstract artifacts are "metaphysical monstrosities". 
Acknowledgements: I would like to thank anonymous referees for their useful comments. For their helpful feedback on earlier drafts, I am grateful to Asya Passinsky, Simon Evnine, James Miller, Ned Markosian, Friederike Moltmann, Damiano Costa, and Philipp Blum.

Funding: Funding was provided by Bogazici University Research Fund (Grant No. 10321SUP).

\section{References}

Bennett, Karen. (2017). Making Things Up, Oxford University Press.

Brock, Stuart. (2010). "The Case against Creationism about Fictional Characters", Philosophical Review, Vol. 119(3):337-364.

Cameron, Ross. (2012). "How to be a Nominalist and a Fictional Realist", in Art and Abstract Objects ed. by Christy Mag Uidhir, Oxford: Oxford University Press, pp. 179-196.

Caplan, Ben and Carl Matheson. (2004). “Can a Musical Work be Created?", British Journal of Aesthetics, Vol. 44(2):113-134.

Corkum, Phil. (2008). "Aristotle on Ontological Dependence", Phronesis, 53(1):6592.

Correia, Fabrice. (2005). Ontological Dependence and Cognate Notions, Munchen, Philosophia Verlag. 
Correia, Fabrice. (2008). “Ontological Dependence”, Philosophy Compass, 3(5):10131032.

Cray, D. Wesley. (2017). “Abstract Generationism: A Reply to Friedell”, The Journal of Aesthetics and Art Criticism, 75(3): 289-292.

Deutsch, Harry. (1991). “The Creation Problem”, Topoi, Vol.10:209-225.

Dodd, Julian. (2000). "Musical Works as Eternal Types”, British Journal of Aesthetics, Vol. 40(4): 424-440.

Dodd, Julian. (2002). “Defending Musical Platonism”, British Journal of Aesthetics, Vol. 42(4): 380-402.

Evnine, Simon J. (2009). "Constitution and Qua Objects in the Ontology of Music", British Journal of Aesthetics, Vol. 49 (3): 203-217.

Evnine, Simon J. (2016). Making Objects and Events, Oxford University Press.

Hilpinen, Risto. (2004). "Artifacts". Stanford Encyclopedia of Philosophy.

Hoeltje, M., B. Schnieder, \& A. Steinberg (eds.). (2013), Varieties of Dependence: Ontological Dependence, Grounding, Supervenience, Response-Dependence (Basic Philosophical Concepts), Munich: Philosophia Verlag.

Howell, Robert. (2002). "Types, Initiated and Indicated”, British Journal of Aesthetics, Vol. 42 (2): 105-127.

Fine, Kit. (1995). “Ontological Dependence”, Proceedings of the Aristotelian Society, 95:269-290. 
French, Steven \& Peter Vickers (2011). "Are There No Things that are Scientific Theories?", British Journal for the Philosophy of Science 62 (4 ):771 -804.

Katz, Jerrold J. (2000). Realistic Rationalism. Cambridge: MIT Press.

Koslicki, Kathrin. (2013). “Ontological Dependence: An Opinionated Survey”, in Varieties of Dependence: Ontological Dependence, Grounding, Supervenience, Response-Dependence (Basic Philosophical Concepts) ed. by Benjamin Schnieder, Miguel Hoeltje \& Alex Steinberg, Philosophia Verlag. pp. 31-64.

Levinson, Jerrold. (1980). "What a Musical Work is”, The Journal of Philosophy, Vol. $77(1): 5-28$.

Mag Uidhir, Christy. (2012). "Introduction: Art, Metaphysics, and the Paradox of Standards", in Art and Abstract Objects ed. by Christy Mag Uidhir, Oxford: Oxford University Press, pp. 1-26.

Mag Uidhir, Christy. (2013). Art and Art-Attempts, Oxford: Oxford University Press.

Psillos, Stathis. (2002). Causation and Explanation, McGill-Queen's University Press.

Rosen, Gideon. (2001). “Abstract Objects”, Stanford Encyclopedia of Philosophy.

Rossberg, Marcus. (2012). “Destroying Artworks”, in Art and Abstract Objects ed. by Christy Mag Uidhir, Oxford: Oxford University Press, pp. 62-86.

Schaffer, Jonathan. (2016). "Grounding in the image of causation”, Philosophical Studies, Vol. 173: 49-100.

Schnieder, Benjamin. (2020). “Grounding and Dependence”, Synthese, Vol. 197: 95124. 
Tahko, E. Tuomas and E. Jonathan Lowe. (2015). “Ontological Dependence”, Stanford Encyclopedia of Philosophy.

Thomasson, Amie. (1999) Fiction and Metaphysics, New York: Cambridge University Press.

Thomasson, Amie. (2007) Ordinary Objects, New York: Oxford University Press.

Thomasson, Amie. (2015a) Ontology Made Easy, New York: Oxford University Press.

Thomasson, Amie. (2015b) "Fictional Discourse", in Fictional Objects ed. by Stuart Brock and Anthony Everett, Oxford: Oxford University Press, pp. 256-274.

Trivedi, Saam. (2002). “Against Musical Works as Eternal Types”, British Journal of Aeshtetics, Vol. 42(1): 73-82.

Trogdon, Kelly. (2018) "Inheritance Arguments for Fundamentality", in Reality and its Structure, ed. by R. Bliss \& G. Priest, Oxford University Press, pp. 182-198.

Walters, Lee. (2013) "Repeatable Artworks as Created Types", British Journal of Aesthetics, Vol 53 (4): 461-477. 